\title{
Language barriers restricting access to health care for Indigenous populations
}

\author{
Cite as: CMAJ 2018 June 18;190:E.754-5 doi: 10.1503/cmaj.109-5613
}

Posted on cmajnews.com on May 30, 2018.

$\mathrm{T}$ he lack of health services offered in Indigenous languages is impeding the delivery of care to Indigenous populations, according to Aluki Kotierk, president of Nunavut Tunngavik Incorporated, which administers treaty rights for the 49000 Inuit inhabitants of Nunavut. The first language of $75 \%$ of the Inuit population in Nunavut is Inuktituk, yet patients are unlikely to hear it spoken by health care providers.

"Many Inuit have little faith in the health system," Kotierk said at the Indigenous Health Conference, recently held in Mississauga. "I look forward to the day when an Inuktituk-speaking patient can walk into a clinic and request services in Inuktituk."
The gaps in Nunavut's health system can be addressed only by training local, Inuktituk-speaking health professionals, said Kotierk. With one doctor for every 3000 residents and almost two-thirds of nursing positions vacant, the traditional reliance on professionals from outside the territory has proven inadequate. In many cases, she noted, health care workers who don't speak Inuktituk rely on patients and other staff as informal translators, although they have limited understanding of medical terminology.

Training health care workers who speak local languages can reduce linguistic barriers to receiving adequate health care. A 2015 report by the Office of the Languages Commissioner of Nuna- vut found that language barriers have a negative impact on access to health care, patient confidentiality, access to mental health services, compliance to treatment plans and health care costs. It also affects quality of care, and can lead to misdiagnoses, medical errors and improper medication, states the report.

"Canada should promote Indigenous languages in health care services," said Kotierk, who noted that the federal government earmarked \$89.9 million to promote Indigenous languages in 2017. "How important is communication to you when you go see a doctor or nurse?"

The link between language and health also goes beyond being able to communicate with health workers,

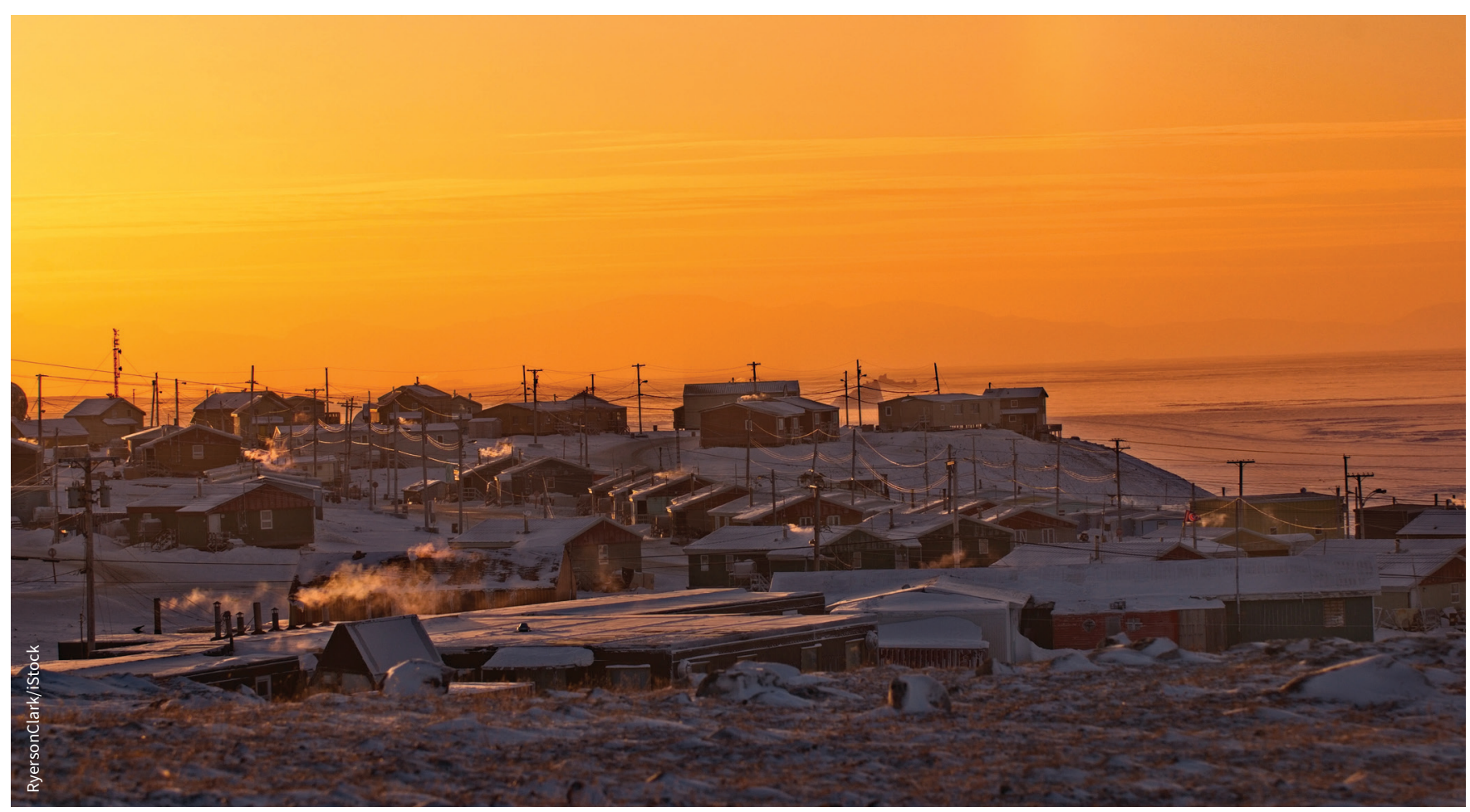

The first language of $75 \%$ of the Inuit population in Nunavut is Inuktituk, yet patients are unlikely to hear it spoken by health care providers. 
according to researchers Andrew Renick and Kevin Shafer of the Canadian Studies Centre at Brigham Young University in Utah. Data from the 2012 Aboriginal Peoples Survey show that Indigenous patients who speak their people's language have lower incidence of asthma, bowel disorders, obesity, anxiety and suicidal thoughts. Those who were more fluent also fared better than those who were only partly fluent.

"High Indigenous language abilities and exposures are protective for all mental health outcomes that we studied, and for several physical health outcomes," said Renick. Language is a good indicator of a patient's "cultural connectedness," he explained. Indigenous Canadians who speak their cultural tongue are more likely to be connected to their culture, which in turn improves their well-being. Likewise, being unable to speak their people's tongue is a red flag of cultural disconnection, which is linked to worse health outcomes.

Other presenters at the conference also emphasized the need for inclusion of Indigenous languages and knowledge, and the community members who possess them, especially in mental health services for Indigenous people. For example, the work of "natural helpers" (mostly elders who speak traditional languages) in a counselling and medical-management program on Wikwemikong First Nation has improved the outcomes of patients with opioid dependencies.

In a speech that emphasized the need for an increase in medical education opportunities for Indigenous peoples, McGill University medical professor Dr. Kent Saylor said that greater attention should be given to traditional approaches to Indigenous health care.

"Hopefully with more Indigenous health care providers, we'll have more health care services delivered in Indigenous languages, and better outcomes," said Saylor. "We need to use our Indigenous knowledge to drive change."

Paul Webster, Toronto, Ont. 